\title{
Treatment of therapy-related acute myeloid leukemia and underlying multiple myeloma with decitabine/venetoclax and daratumumab
}

\author{
Khalid Shoumariyeh ${ }^{1}$. Johannes Jung ${ }^{1} \cdot$ Michael Rassner $^{1} \cdot$ Sandra Maria Dold ${ }^{1,2} \cdot$ Veronika Riebl $^{1} \cdot$ Milena Pantic $^{1}$. \\ Georg Herget $^{3,4} \cdot$ Reinhard Marks $^{1,3} \cdot$ Michael Lübbert ${ }^{1,3} \cdot$ Ralph Wäsch $^{1,3} \cdot$ Monika Engelhardt $^{1,3}$ (D)
}

Received: 15 February 2021 / Accepted: 2 March 2021 / Published online: 13 March 2021

(C) The Author(s) 2021

\section{Dear Editor,}

With increased survival of patients with multiple myeloma (MM), therapy-related myelodysplastic syndrome (t-MDS) and $\mathrm{t}$-acute myeloid leukemia (AML) may occur more frequently $[1,2]$. We present here a patient with high-risk (HR) MM, who developed t-MDS and subsequent t-AML. AML treatment with decitabine/venetoclax resulted in complete remission (CR) of the t-AML, while progressive disease of MM was treated with daratumumab. We hypothesize that upregulation of CD38 in bone marrow plasma cells (BMPCs) after decitabine/venetoclax may have enhanced MM response. Additionally, we performed a review of the literature (Suppl. Table 1).

In June 2015, a 64-year-old female was diagnosed with IgG kappa ( ) MM. IgG levels were $46 \mathrm{~g} / \mathrm{L}$, $\mathrm{K}$-serum-free light chains (SFLC) $75.4 \mathrm{mg} / \mathrm{L}$ and $\beta 2$-microglobulin $8.2 \mathrm{mg} / \mathrm{L}$ (Fig. 1A). Anemia with a hemoglobin $(\mathrm{Hb})$ of $8.4 \mathrm{~g} / \mathrm{dL}$ and osteolytic lesions were present. BMPC infiltration was $90 \%$, and fluorescence in situ hybridization (FISH) revealed hyperdiploidy and del17p13 (Fig. 1B (a) and C). The MM was classified as International Staging System (ISS) III, R-

Monika Engelhardt

monika.engelhardt@uniklinik-freiburg.de

1 Department of Hematology, Oncology and Stem Cell Transplantation, Medical Center - University of Freiburg, Faculty of Medicine, University of Freiburg, Hugstetterstr. 53, 79106 Freiburg, Germany

2 Faculty of Biology, University of Freiburg, Freiburg, Germany

3 Comprehensive Cancer Center Freiburg (CCCF), Faculty of Medicine, Medical Center - University of Freiburg, Freiburg, Germany

4 Department of Orthopedics and Trauma Surgery, Faculty of Medicine, Medical Center - University of Freiburg, Freiburg, Germany
ISS III, with 2/4 CRAB criteria. The patient's revised myeloma comorbidity index was intermediate-fit [3].

First-line therapy with bortezomib, cyclophosphamide, and dexamethasone was followed by autologous stem cell transplantation and maintenance therapy with lenalidomide (Fig. $1 \mathrm{~A})$. After $1 \frac{1 / 2}{2}$ years $(11 / 2017)$, lenalidomide was discontinued due to worsening anemia $(\mathrm{Hb} 10 \mathrm{~g} / \mathrm{dL})$ and leukopenia $\left(2.8 \times 10^{6} / \mathrm{L}\right)$. BM assessment did not reveal increased PCs or MDS, and serological parameters indicated stable disease.

In January 2019, pancytopenia worsened $(\mathrm{Hb} 8.4 \mathrm{~g} / \mathrm{dL}$, leukocytes $0.59 \times 10^{6} / \mathrm{L}$, platelets $12 \times 10^{6} / \mathrm{L}$ ) and $\mathrm{k}$-SFLCs increased (Fig. 1A). Another BM biopsy revealed BMPCs of $50 \%$ and myeloid blasts of $22 \%$ (Fig. 1B (b)). Molecular analyses identified mutations in DNMT3A and IDH1 (Fig. 1C). Coexistence of MM and t-AML (Fig. 1D, left) was confirmed by 10 -color multiparameter flow cytometry (MFC) analysis of the BM [4].

Due to frailty at that time, she was ineligible for intensive AML induction therapy. Therefore, treatment with decitabine/ venetoclax was started in February 2019. A BM biopsy in March 2019 confirmed CR of the t-AML (Fig. 1B (c)). However, PCs assessed by immunohistochemistry for CD38 had increased to $90 \%$, and MFC confirmed aberrant PCs (aPCs) (Fig. 1D, right); therefore $2^{\text {nd }}$ line daratumumab treatment was initiated (Fig. 1A). This induced VGPR and peripheral blood (PB) counts improved ( Hb 10.2g/dL, leukocytes $3.2 \times 10^{6} / \mathrm{L}$, platelets $94 \times 10^{6} / \mathrm{L}$ ).

In June 2019, after worsening pancytopenia re-emerged and myeloid blasts were detectable in PB smears, decitabine/venetoclax was re-initiated. The BM biopsy in August 2019 showed persisting (30\%) immature myeloid blasts (Fig. 1B (d)), upon which melphalan per os was started [5]. The patient died 2 months later of t-AML/ MM progression, 50 months after the diagnosis of HR $\mathrm{MM}$, and 9 months after t-AML. 


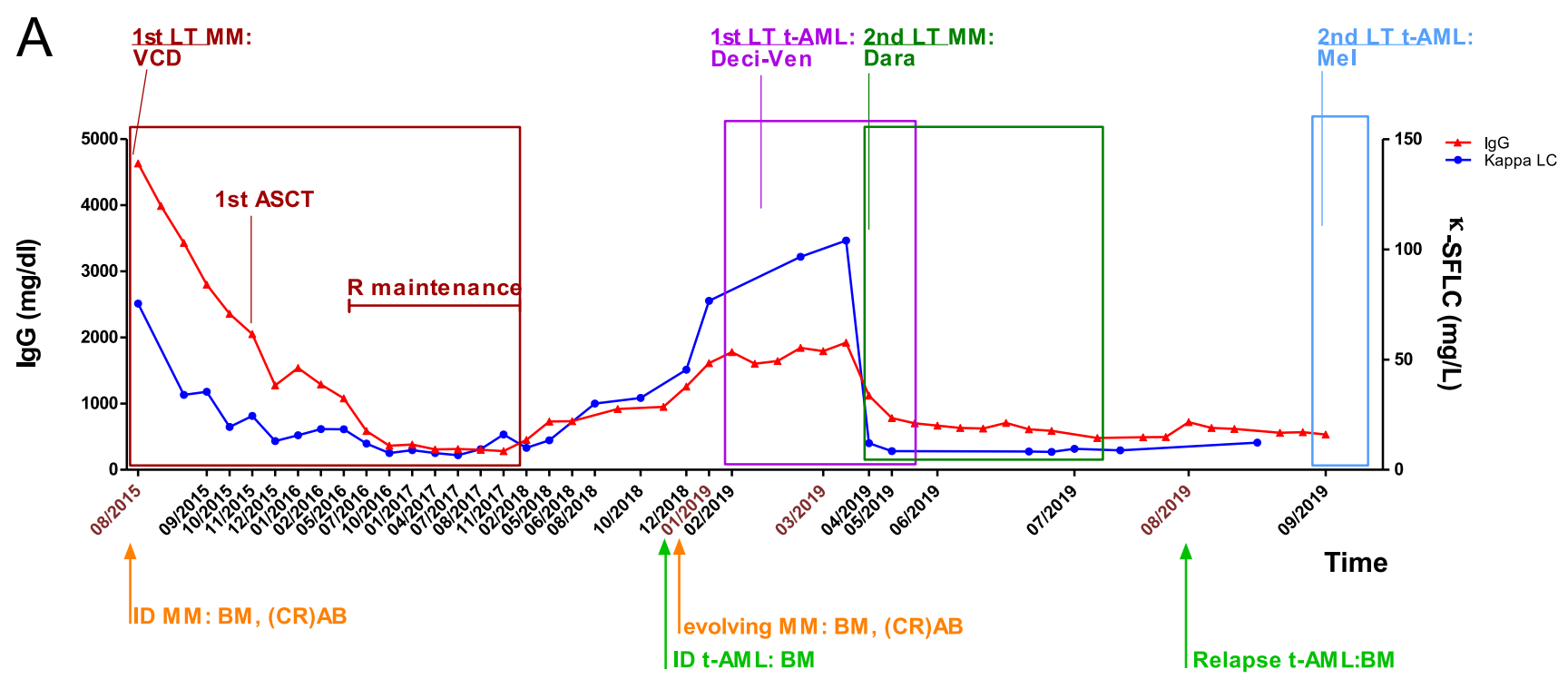

B

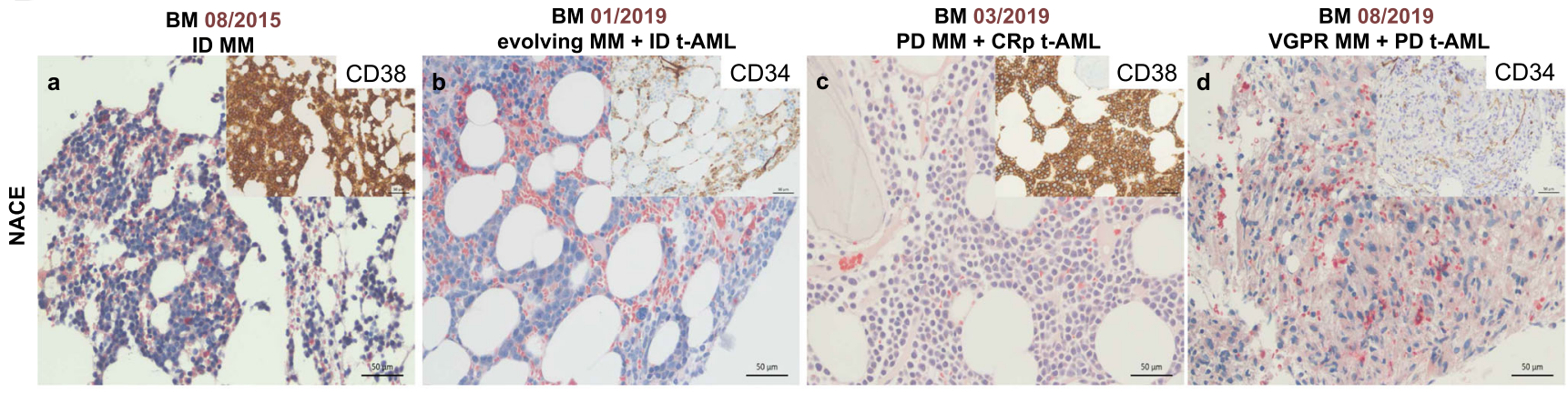

C

\begin{tabular}{lcccc}
\hline Date & $\mathbf{0 8 / 2 0 1 5}$ & $01 / 2019$ & $03 / 2019$ & $08 / 2019$ \\
$\begin{array}{l}\text { Disease } \\
\text { Stage }\end{array}$ & ID MM & evolving MM & PD MM & VGPR MM \\
& - & ID t-AML & CRpt-AML & Relapse t-AML \\
\hline FISH & $\begin{array}{c}\text { Hyperdiploidy/del 17p13 } \\
(60 \%)\end{array}$ & $\begin{array}{c}\text { Hyperdiploidy/del 17p13 } \\
(30 \%)\end{array}$ & $\begin{array}{c}\text { Hyperdiploidy/del 17p13 } \\
(60 \%)\end{array}$ & No Hyperdiploidy/del 17p13 \\
\hline MA & not done & IDH1 (30\%) & IDH1 (20\%) & IDH1 (20\%)
\end{tabular}

D

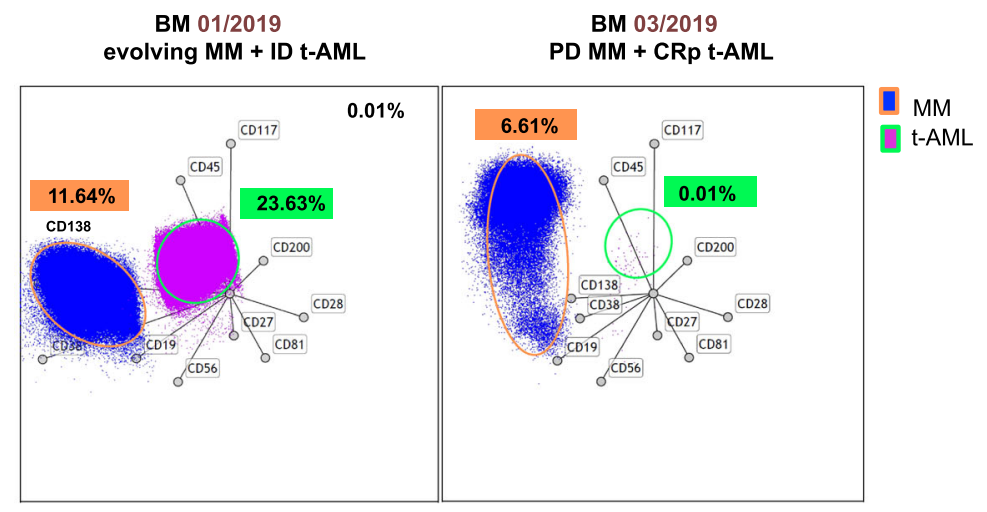

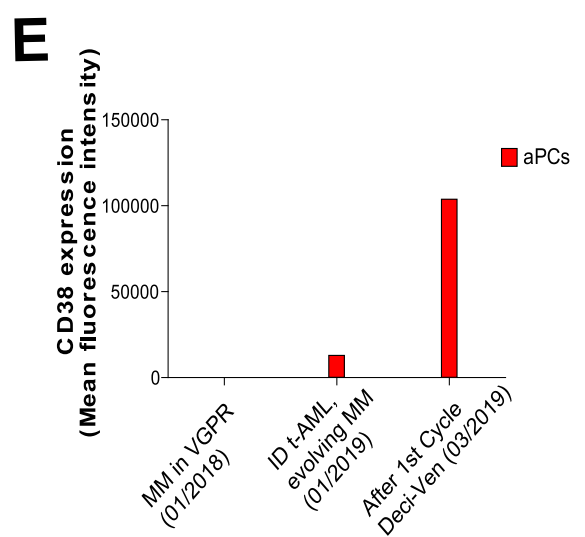


Fig. 1 The patient's clinical, cytogenetic, and molecular results, describing both MM and t-AML clones. A Course of serological parameters (IgG and $\mathrm{k}$-SFLC) and disease state of MM (orange) and t-AML (green) between August 2015 and September 2019. Lines of treatment for each entity are depicted. B NACE and immunohistochemical stainings (CD34 or CD38) of BM biopsies from initial diagnosis of MM (a. August 2015), initial diagnosis of t-AML (b. January 2019), after the $1^{\text {st }}$ cycle of decitabine/venetoclax (c. March 2019), and at t-AML relapse (d. August 2019). C Remission status (gray), fluorescence in situ hybridization (FISH) analyses (beige), and molecular diagnostics (blue) during the disease course. Percent of cells positive for hyperdiploidy and/or del17p13 as assessed by FISH at initial diagnosis of MM (August 2015), at initial diagnosis of t-AML (January 2019), and before treatment initiation with daratumumab (March 2019). Allele frequency of the IDH1 mutation at initial diagnosis of t-AML (January 2019), after the $1^{\text {st }}$ cycle decitabine/ venetoclax (March 2019), and at t-AML relapse (August 2019). D Radar plot of the flow cytometry analysis with the 10-color MFC panel, showing the myeloma (dark blue/orange circle) and leukemia (pink/green circle) population at the initial diagnosis of t-AML (January 2019) and after the $1^{\text {st }}$ cycle of decitabine/venetoclax (March 2019). E Mean fluorescence intensity of CD38 expression of aberrant plasma cells (aPCs) in the BM in January 2018, when the MM was in remission, at initial diagnosis of tAML (January 2019) and after the $1^{\text {st }}$ cycle of decitabine/venetoclax (March 2019). aPC, aberrant plasma cells; ASCT, autologous stem cell transplantation; $\mathrm{BM}$, bone marrow; $\mathrm{CRAB}$, hypercalcemia, renal impairment, anemia, bone lesions; CRp, complete remission with incomplete platelet recovery; Dara, daratumumab; Deci-Ven, decitabine/venetoclax; $1^{\text {st }}$ LT MM, first-line treatment multiple myeloma; $1^{\text {st }}$ LT t-AML, firstline treatment therapy-related acute myeloid leukemia; FISH, fluorescence in situ hybridization; ID, initial diagnosis; IDH1, isocitrate dehydrogenase 1; IgG, immunoglobulin G; LC, light chains; $2^{\text {nd }}$ LT MM, second-line treatment multiple myeloma; Mel, melphalan; MA, molecular analysis; NACE, naphthol-AS-D-chloracetatesterase; PD, progressive disease; R, Lenalidomide; SFLC, serum-free light chains; VCD, bortezomib, cyclophosphamide, dexamethasone; VGPR, very good partial remission

In summary, after decitabine/venetoclax induction and favorable t-AML-response, $\mathrm{MM}$ progression required $2^{\text {nd }}$ line daratumumab treatment, resulting in VGPR and improvement of PB counts. Notably, decitabine/venetoclax may have resulted in upregulation of CD38 (Fig. $1 \mathrm{D}$ and E), possibly augmenting the response to daratumumab, although single-cell CD38 expression on aPCs before and after decitabine/ venetoclax was not performed. In line with this hypothesis, Choudhry et al. showed that treatment of MM cell lines and primary patient samples with the demethylating agent 5 azacytidine resulted in CD38 upregulation [6]. Moreover, ATRA and the pan-deacetylase-inhibitor panobinostat may increase expression of CD38 in MM [7, 8]. Similarly, Zhao et al. demonstrated upregulation of CD38 on CD8-positive Tcells of AML patients receiving decitabine [9]. Furthermore, daratumumab has been shown to be effective in targeting adult CD38-positive AML and T-cell acute lymphoblastic leukemia (T-ALL) as well as pediatric T-ALL blasts in a preclinical patient-derived xenograft mouse model, and a phase II study
(NCT03384654) investigating the efficacy of daratumumab in relapsed and refractory T-ALL is currently ongoing $[10,11]$. Recently, Berthon et al. reported about a patient with simultaneous AML and MM who concomitantly received 5azacytidine and daratumumab during MM relapse (Suppl. Table 1) [12]. Clinical trials are currently under way to investigate whether pretreatment with demethylating agents enhances the efficacy of daratumumab.

Supplementary Information The online version contains supplementary material available at https://doi.org/10.1007/s00277-021-04490-3.

Acknowledgements The authors thank distinguished IMWG, EMN, DSMM, and GMMG myeloma experts for their advice, recommendations, and insightful, inspiring comments.

Author contribution K.S. designed the study, interpreted the data, and wrote the manuscript; J.J. and M.R. interpreted the data and wrote the manuscript; S.M.D. and V.R. performed FACS experiments and analyze and wrote the manuscript; M.P. performed cytogenetic analyses and provided information; G.H. provided patient data and wrote the manuscript; M.L., R.M. and R.W. helped with the conception and design of the study; M.E. designed the study, interpreted the data, and wrote the manuscript.

Funding Open Access funding enabled and organized by Projekt DEAL. This work has been supported by the University of Freiburg "research on cancer"/Forschungskommission. This work was supported by the Deutsche Krebshilfe (grants 1095969 and 111424 (to ME and RW)). JJ was supported by an EXCEL-Fellowship of the Faculty of Medicine, funded by the Else Kröner-Fresenius-Stiftung.

\section{Declarations}

Ethics Informed consent was obtained from the patient for being included in this study.

Conflict of interest JJ, MR, SMD, VR, MP, GH, RM, ML have no financial or other relationships that might lead to a conflict of interest. KS has received travel support from Abbvie and consultancy fees from Novartis. RW has received research and travel support from Sanofi, Gilead, Jazz, Celgene, and Amgen and has received consultancy fees from Sanofi, Pfizer, Gilead, Novartis, Amgen, and Takeda. ME has received educational and trial support from Amgen, Takeda, BMS, Janssen, and Novartis, in all unrelated to this case.

Open Access This article is licensed under a Creative Commons Attribution 4.0 International License, which permits use, sharing, adaptation, distribution and reproduction in any medium or format, as long as you give appropriate credit to the original author(s) and the source, provide a link to the Creative Commons licence, and indicate if changes were made. The images or other third party material in this article are included in the article's Creative Commons licence, unless indicated otherwise in a credit line to the material. If material is not included in the article's Creative Commons licence and your intended use is not permitted by statutory regulation or exceeds the permitted use, you will need to obtain permission directly from the copyright holder. To view a copy of this licence, visit http://creativecommons.org/licenses/by/4.0/. 


\section{References}

1. Leone G, Pagano L, Ben-Yehuda D, Voso MT (2007) Therapyrelated leukemia and myelodysplasia: susceptibility and incidence. Haematologica. 92:1389-1398. https://doi.org/10.3324/haematol. 11034

2. Engelhardt M, Ihorst G, Landgren O, Pantic M, Reinhardt H, Waldschmidt J, May AM, Schumacher M, Kleber M, Wasch R (2015) Large registry analysis to accurately define second malignancy rates and risks in a well-characterized cohort of 744 consecutive multiple myeloma patients followed-up for 25 years. Haematologica. 100:1340-1349. https://doi.org/10.3324/ haematol.2015.127548

3. Engelhardt M, Domm A-S, Dold SM, Ihorst G, Reinhardt H, Zober A, Hieke S, Baayen C, Müller SJ, Einsele H, Sonneveld P, Landgren O, Schumacher M, Wäsch R (2017) A concise revised myeloma comorbidity index as a valid prognostic instrument in a large cohort of 801 multiple myeloma patients. Haematologica. 102:910-921. https://doi.org/10.3324/haematol.2016.162693

4. Dold SM, Riebl V, Wider D, Follo M, Pantic M, Ihorst G et al (2020) Validated single-tube multiparameter flow cytometry approach for the assessment of minimal residual disease in multiple myeloma. Haematologica. 105:e523. https://doi.org/10.3324/ haematol.2019.238394

5. Stratmann J, van Kann E, Rummelt C, Koschade S, Röllig C, Lübbert M, Schaich M, Parmentier S, Sebastian M, Chromik J, Becker von Rose A, Ballo O, Steffen B, Serve H, Brandts C, Shaid S (2019) Low-dose melphalan in elderly patients with relapsed or refractory acute myeloid leukemia: a well-tolerated and effective treatment after hypomethylating-agent failure. Leuk Res 85:106192. https://doi.org/10.1016/j.leukres.2019.106192

6. Choudhry P, Mariano MC, Geng H, Martin TG, Wolf JL, Wong SW et al (2020) DNA methyltransferase inhibitors upregulate CD38 protein expression and enhance daratumumab efficacy in multiple myeloma. Leukemia. 34:938-941. https://doi.org/10. 1038/s41375-019-0587-5

7. García-Guerrero E, Gogishvili T, Danhof S, Schreder M, Pallaud C, Pérez-Simón JA, Einsele H, Hudecek M (2017) Panobinostat induces CD38 upregulation and augments the antimyeloma efficacy of daratumumab. Blood. 129:3386-3388. https://doi.org/10. 1182/blood-2017-03-770776

8. Bat-Erdene A, Nakamura S, Oda A, Iwasa M, Teramachi J, Ashtar M, Harada T, Miki H, Tenshin H, Hiasa M, Fujii S, Sogabe K, Oura M, Udaka K, Kagawa K, Yoshida S, Aihara KI, Kurahashi K, Endo I, Abe M (2019) Class 1 HDAC and HDAC6 inhibition inversely regulates $\mathrm{CD} 38$ induction in myeloma cells via interferon- $\alpha$ and ATRA. Br J Haematol 185:969-974. https://doi.org/10.1111/bjh. 15673

9. Zhao C, Jia B, Wang M, Schell TD, Claxton DF, Ehmann WC, Rybka WB, Mineishi S, Naik S, Songdej N, Sivik JM, Hohl RJ, Zeng H, Zheng H (2020) Multi-dimensional analysis identifies an immune signature predicting response to decitabine treatment in elderly patients with AML. Br J Haematol 188:674-684. https:// doi.org/10.1111/bjh.16228

10. Bride KL, Vincent TL, Im SY, Aplenc R, Barrett DM, Carroll WL, Carson R, Dai Y, Devidas M, Dunsmore KP, Fuller T, GlisovicAplenc T, Horton TM, Hunger SP, Loh ML, Maude SL, Raetz EA, Winter SS, Grupp SA, Hermiston ML, Wood BL, Teachey DT (2018) Preclinical efficacy of daratumumab in T-cell acute lymphoblastic leukemia. Blood. 131(9):995-999. https://doi.org/10.1182/ blood-2017-07-794214

11. Naik J, Themeli M, de Jong-Koorlar R, Ruiter RWJ, Poddighe PJ, Yuan $\mathrm{H}$ et al (2019) CD38 as a therapeutic target for adult acute myeloid leukemia and T-cell acute lymphoblastic leukemia. Haematologica. 104(3):e100-e103. https://doi.org/10.3324/ haematol.2018.192757

12. Berthon C, Nudel M, Boyle EM, Goursaud L, Boyer T, Marceau A, Quesnel B (2020) Acute myeloid leukemia synchronous with multiple myeloma successfully treated by azacytidine/lenalidomide and daratumumab without a decrease in myeloid clone size. Leuk Res Rep 13:100202. https://doi.org/10.1016/j.lrr.2020.100202

Publisher's note Springer Nature remains neutral with regard to jurisdictional claims in published maps and institutional affiliations. 